\title{
Changing the Home Visiting Research Paradigm: Models' Perspectives on Behavioral Pathways and Intervention Techniques to Promote Good Birth Outcomes
}

Anne K Duggan ( $\square$ aduggan@jhu.edu )

Johns Hopkins University https://orcid.org/0000-0002-3465-3662

Kelly M Bower

Johns Hopkins University School of Nursing

Ciara Zagaja

Johns Hopkins University Bloomberg School of Public Health

Kay O'Neill

Johns Hopkins University Bloomberg School of Public Health

Deborah Daro

Chapin Hall at the University of Chicago

\section{Kathryn Harding}

Healthy Families America at Prevent Child Abuse America

Allison Ingalls

Center for American Indian Health, Johns Hopkins University Bloomberg School of Public Health

Allison Kemner

Parents as Teachers

Crista Marchesseault

Minding the Baby, Yale Child Study Center \& Yale School of Nursing

William Thorland

Nurse-Family Partnership

\section{Research}

Keywords: precision services, home visiting, intervention techniques, birth outcomes

Posted Date: January 27th, 2021

DOl: https://doi.org/10.21203/rs.3.rs-154026/v1

License: @) (i) This work is licensed under a Creative Commons Attribution 4.0 International License. Read Full License 


\section{Abstract}

Background: The US is scaling up evidence-based home visiting to promote health equity in expectant families and families with young children. Persistently small average effects for full models argue for a shift in the research paradigm to understand what interventions within full models work best, for which families, in which contexts, why, and how. Historically, the complexity and proprietary nature of most evidence-based models have been barriers to such research. To address this, stakeholders are building the Precision Paradigm, a common framework and language to define and test interventions and their mediators and moderators. This observational study applied portions of the Paradigm to describe models' intended behavioral pathways to good birth outcomes and their stance on home visitors' use of specific intervention techniques to promote families' progress along intended pathways.

Methods: Five of the six eligible evidence-based models participated. Model representatives independently completed three structured surveys focused on 41 intended behavioral pathways and 23 behavior change technique categories. Survey data were used to describe: the number and nature of models' intended behavioral pathways to good birth outcomes; the behavior change techniques they required or recommended home visitors to use; the relative emphasis given to required/recommended techniques; the compatibility of other techniques with their model; and the consistency of their stance on techniques across intended pathways.

Results: Models defined 31.6 intended pathways on average but varied in their number of intended pathways (range 16-41) and the nature of such pathways. They varied in the number of technique categories they required (mean 3.2, range 0-8.9) or recommended (mean 10.6, range 1.5-20.0) that home visitors use. That said, all models rated nearly all technique categories as at least compatible with their model, even if not explicitly required or recommended. Within intended pathways, models varied in the relative emphasis to give to specific techniques. Models varied in the consistency of their requirements and recommendations for using specific techniques across intended pathways.

Conclusions: The Precision Paradigm is a promising resource to accelerate innovative cross-model research to clarify which interventions within home visiting work best for which families, in which contexts, why and how.

\section{Contributions To The Literature}

- The prevailing research paradigm for home visiting has been randomized trials of full models to estimate average effects on outcomes.

- Persistent challenges in engaging and positively impacting families calls for a new paradigm to answer, What works best, for which families, in which contexts, why and how?

- Our structured approach identified models' intended behavioral pathways and stance on specific behavior change techniques to promote good birth outcomes.

- This approach can be used with other outcomes and stakeholder groups to assess existing models' coherence and clarity and existing implementation system adequacy, and to design new interventions concordant with existing evidence-based models.

\section{Background}

Early childhood home visiting is a preventive service strategy for expectant families and families with children birth to five years. It provides education and support to promote health equity in families facing multiple adversities such as poverty, poor access to healthcare, systemic racism, histories of trauma, parental behavioral health issues, and lack of parenting expertise.

In 2010 and again in 2018, Congress authorized federal investment to scale up evidence-based home visiting through the Maternal, Infant and Early Childhood Home Visiting Program (MIECHV Program). ${ }^{1,2}$ The MIECHV Program is administered by the Health Resources and Services Administration and the Administration for Children and Families. Most funding is awarded to states and territories to expand evidence-based home visiting availability, usually through contracts with community-based organizations and local implementing agencies. Some award funding is dedicated to tribes, tribal organizations, and urban Indian organizations to develop, implement, and evaluate home visiting programs in American Indian and Alaska Native communities. 
Many of the 19 home visiting models designated as evidence-based for MIECHV Program purposes are comprehensive, aiming to promote a broad range of outcomes through frequent visits over many months or a few years. ${ }^{3}$ All models aim to promote child well-being. They vary in the parenting, family functioning, and other factors they address to promote child well-being, and in their theories of change. All models provide direct service; most also link families with community resources.

Population-level change through scale up of evidence-based interventions requires reaching intended families, engaging them, and implementing services with fidelity. ${ }^{4}$ The MIECHV Program's national evaluation - an 88-site, cross-model study of family reach and engagement, implementation and impact - provides valuable insights on these aspects of the scale up of evidence-based models of home visiting. The implementation study found that local programs reached intended families but failed to engage many of them. ${ }^{5}$ It also found that local programs' implementation systems were uneven, providing stronger support for staff to address parenting directly than to address its contributing factors. Study results showed that this unevenness was reflected in service delivery. ${ }^{5}$ Home visiting significantly improved several postnatal confirmatory outcomes but with very small average effects. $^{6,7}$

The concordance of these results with those of earlier research reveals weaknesses of the traditional home visiting research paradigm for refining models and implementation systems to advance the field. For the past several decades, the field's traditional research paradigm has been to use randomized trials to estimate average effects of full home visiting models. Research reports have typically described models' theories of change and model components in broad terms, assessed fidelity and family engagement only lightly, if at all, and restricted testing for subgroup impacts to post hoc analyses. This research paradigm has been essential for building the evidence base for full models but has been inadequate to inform strategies to strengthen family engagement, fidelity of implementation, and impacts on outcomes across models. It has been inadequate as well for advancing the field's understanding of home visiting's core components. ${ }^{8}$

Open science can improve research reporting to promote replication of results and effective scale up, ${ }^{9}$ but only insofar as home visiting embraces a research paradigm that can answer the question, What works best, for which families, in which contexts, why and how? ${ }^{10,11}$ For home visiting, this requires: 1) specifying and testing interventions within home visiting rather than full models themselves; 2) going beyond estimating average effects on outcomes by testing mediators and moderators; and 3) using innovative designs to achieve actionable results and optimize impacts across varied contexts. Such an approach, if coupled with a standard framework and language across home visiting models and studies, can accelerate improvements in models and implementation systems, and the confidence of decision-makers who rely on research to guide their policy and programming decision-making.

Home visiting models are complex interventions, for sure, but advancement of the field now requires a more granular approach in defining and testing home visiting's component parts. ${ }^{12}$ Recognition of the benefits of a granular approach has motivated a shift in this direction beyond home visiting. Examples include the distillation of approaches used within manualized mental health treatments for adolescents, ${ }^{13}$ the deconstruction of interventions to address obesity into their component behavior change techniques, ${ }^{14}$ identification of the content and relational components of motivational interviewing, ${ }^{15}$ and analysis of provider-client interactions into task-, social-emotional-, and activation-focused strategies. ${ }^{16}$ Pioneering researchers use different strategies to organize the range of potential behavior change components of interventions. One option is hierarchical taxonomies of highly standardized terms to facilitate systematic reviews and meta-analytic studies. ${ }^{17}$ Another is to organize theory-based intervention techniques by the mechanisms of action they are likely to influence, to facilitate intervention development. ${ }^{18}$

Several features of home visiting complicate shifting the research paradigm. Most models are proprietary; this can inhibit sharing of detailed information on interventions. Many models are complex and comprehensive, comprised of interwoven interventions whose intended independent and interactive effects might not yet be fully and explicitly conceptualized. Many comprehensive models were designed with the long view in mind; focusing on short-term target behaviors requires changing focus. Some models are grounded more in explanatory theories than in theories of behavior change.

The Home Visiting Applied Research Collaborative (HARC) is a national research and development platform charged with shifting the home visiting paradigm. ${ }^{10,11,19,20}$ HARC brings together stakeholders - model developers, researchers, administrators, front 
line staff and families - to build and use a common research framework and language to advance precision.

Figure 1 illustrates key components of the evolving framework, called the Precision Paradigm. It is based on the ontology of the Behaviour Change Project, arguably the most widely disseminated ontology for behavioral health interventions. ${ }^{21}$ We chose this as the basis for the Precision Paradigm because it is applicable for intervention research across diverse outcomes and contexts, just as home visiting aims to achieve diverse outcomes in diverse contexts. The Paradigm explicitly cites home visiting experience as well as theory and empirical evidence to reflect the field's commitment to partnership across stakeholder groups and thus the central role of families and front-line providers in intervention design and testing.

\section{Study Purpose}

One foundational aspect of this work is to characterize the interventions currently comprising evidence-based home visiting models in a granular, standardized, and generic way. This was the broad goal of the project reported here, which focused specifically on interventions to promote good birth outcomes. The project identified models' intended behavioral pathways to good birth outcomes and their stance on home visitors' use of specific intervention techniques to promote families' progress along intended pathways. It was intended as a pilot test of methods that could be used to define behavioral pathways and intervention techniques across other intended home visiting outcomes.

We focused the pilot test on home visiting interventions to promote good birth outcomes for three reasons. First, birth outcomes are highly variable across population subgroups and thus are a major public health concern. Second, this 'test of concept' project could be carried out more efficiently by collaborating with a small number of evidence-based models - the subset whose range of intended outcomes includes birth outcomes. Lastly, the project could draw on a solid body of research on major risks contributing to poor birth outcomes and maternal behaviors to reduce those risks.

\section{Methods}

Co-authors affiliated with HARC's coordinating center conceptualized and designed the observational study, gathered and analyzed data, interpreted study results, and drafted and revised this manuscript. The Strengthening the Reporting of Observational Studies in Epidemiology (STROBE) guidelines for reporting observational studies ${ }^{22}$ was used to ensure rigorous reporting of the study (see additional information). National model leadership identified staff to take the lead as their representatives and co-authors for this study. Co-authors representing home visiting models provided study data, interpreted results, and revised the manuscript. Figure 2 illustrates how sample selection and data collection mapped to the Precision Paradigm.

\section{Selection of Home Visiting Models}

The intended sample was evidence-based models enrolling families prenatally to promote healthy birth outcomes. We identified models meeting three criteria: designated as evidence-based by the Home Visiting Evidence of Effectiveness (HomVEE) review; implemented in states or tribal communities in the United States; and enrolling families prenatally. Eight models met these criteria. We contacted each model's national office to ascertain whether the model aimed to prevent premature birth or low birth weight, defined as a birth $<37$ weeks gestation and a birth weight $<2500$ grams. Two of the eight models indicated that promoting healthy birth outcomes was not a central focus. The other six models indicated that improving birth outcomes was one of their intended outcomes. Five agreed to participate in the project: Family Spirit, Kentucky's Health Access Nurturing Development Services (HANDS), Healthy Families America, Minding the Baby, Nurse-Family Partnership, and Parents as Teachers. State administrators for the sixth model, HANDS, declined due to demands of the COVID-19 pandemic.

\section{Data Collection}

Model representatives three surveys mapped to the Precision Paradigm (Figure 2). The surveys worked backward, from ascertaining the risks the model aimed to reduce, to the maternal behaviors it aimed to promote to reduce those risks, to the techniques it endorsed visitors to use to promote those behaviors and the emphasis to give to each.

HARC coordinating center investigators distributed each survey to model representatives at the same time, for independent completion within 2-3 weeks. Surveys 2 and 3 were distributed after all models had completed the preceding survey. HARC 
coordinating center investigators encouraged model representatives to ask for clarification if they were uncertain how to answer a question. Model representatives submitted seven questions. HARC investigators emailed responses to all five models by the next working day.

\section{Measurement}

Survey 1 - Intended Pathways. HARC investigators drew from the literature $23,24,25,26,27$ and from relevant American College of Obstetrics and Gynecologists Committee Opinions ${ }^{28}$ to identify modifiable risks for low birth weight and premature birth, and target behaviors to reduce these risks.

To minimize respondent burden, Part 1 of Survey 1 was limited to ten common, diverse, modifiable, evidence-based risk factors that could be reduced through home visiting and that fell within the scope of the current pregnancy. The risks fell into four groups: 1) health care use (inadequate prenatal care); 2) psychosocial well-being (high stress, depression, intimate partner violence); 3 ) behavioral health (tobacco use, alcohol use, illicit drug use); and 4) biologic risk factors (infection, diabetes, high blood pressure). The survey asked representatives to rate the priority their model gave to reducing each risk. Response choices were: not a priority, low priority, moderate priority, high priority, and not sure. A priority risk was defined as one whose reduction was designated as a low, moderate, or high priority.

Part 2 of the survey focused on 14 behaviors that could be promoted within home visiting for the current pregnancy. The behaviors fell into four groups: 1) basic health promotion (physical activity, healthy diet, stress reduction activities, social supports); 2) health care use (adherence to prenatal care visit schedule, engagement in substance use treatment, and alerting the prenatal care provider to warning signs; 3 ) behavioral health (stopping or reducing tobacco use, stopping or reducing alcohol use, stopping or reducing illicit drug use); and 4) specific risk reduction behaviors (condom use, developing a domestic violence safety plan, medication adherence, self-monitoring of physiologic indicators). The survey asked representatives to rate their models' expectations of home visitors for promoting specific maternal behaviors to reduce each of its priority risks. Response choices were required, recommended but not required, no expectation but compatible with our model, not compatible with our model, and not sure. A target behaviorwas defined as a behavior the model either required or recommended visitors to promote.

The ten risks and 14 behaviors together defined 41 unique pathways to good birth outcomes (Table 1). The literature recommended some behaviors as a way reduce multiple risks. For example, physical activity is a behavior to reduce high stress, depression, high blood pressure and diabetes. Of note, the literature characterized three risk factors - tobacco use, alcohol use and inadequate prenatal care - not only as risk factors but as behaviors influencing other risk factors. In the same way, we defined these three constructs as both risk factors and maternal behaviors.

At the end of Survey 1, HARC coordinating center investigators used each model's priority risks and target behaviors to define its intended pathways to good birth outcomes. An intended pathway for a model is one linking a target behavior with a priority risk. Each model could have up to 41 intended pathways; the number and nature of intended pathways depended on the model's priority risks and target behaviors to reduce those risks.

Survey 2 - Endorsement of Intervention Technique Categories in Intended Pathways: Survey 2 asked respondents to rate their models' stance regarding home visitors' use of each of 23 technique categories for each of its intended pathways. Response choices were required, recommended but not required, no expectation but compatible with our model, not compatible with our model, and not sure. An endorsed technique category was defined as one that the model required or recommended visitors to use for a specific intended pathway.

The Appendix describes the 23 technique categories. HARC coordinating center investigators defined them by adapting an existing taxonomy of behavior change techniques and by adding techniques commonly used in home visiting but not represented in the existing taxonomy. The existing taxonomy contained 93 techniques grouped into 16 categories. ${ }^{16}$ We used techniques categories rather than individual techniques to reduce respondent burden. We modified these categories in four ways: 1) split four of the original categories into eight narrower, more homogeneous categories; 2) dropped one of the original categories but assigned some of its techniques to another existing category; 3 ) added the category, "assess readiness for change," because it is concordant with a family-centered approach and with theories of behavior change that differentiate motivating, enabling, and reinforcing 
target behaviors; ${ }^{29}$ and 4 ) added three categories aligned with the framework of West et al. ${ }^{30}$ to reflect home visiting's use of referral and coordination.

Survey 3 - Emphasis in Using Endorsed Technique Categories: Survey 3 explored how much models expected home visitors to emphasize technique categories within and across intended pathways. To minimize respondent burden while maximizing the number of comparisons that could be made, the survey focused on 20 pathways defined by four behaviors associated with four to six different risks and designated as target behaviors by all five models.

For each model, Survey 3 was limited to the model's intended pathways and the technique categories it had endorsed for those pathways. For each intended pathway, model representatives rated the relative emphasis their model expected visitors to give to each endorsed technique category. Response choices were adapted from those of Smith et $\mathrm{al}^{31}$ and ranged from one (low emphasis) to five (high emphasis) and no stance. Response choices two through four were not labeled. A technique category with a rating of five was defined as a high-emphasis technique category.

\section{Analysis}

HARC coordinating center investigators carried out data analyses. After all surveys had been completed, they shared results with model representatives in several iterations, using representatives' feedback to guide new analyses and to improve the clarity and usefulness of results.

Priority Risks, Target Behaviors and Intended Pathways: We described the distribution of model responses for each risk. We determined and graphed the number of models designating each of Table 1's 41 pathways as an intended pathway.

Stance on Technique Categories: We calculated the distribution of each model's responses (required, recommended, no expectation but compatible, not compatible, and not sure) for each technique category across all of its intended pathways combined. For all models combined, we calculated the means of the model-specific distribution of responses. We calculated the number of models designating each technique category as a high-emphasis technique category within each intended pathway.

Overview and Comparison of Models' Priority Risks, Intended Pathways, and Stance on Technique Categories: For each model, we calculated the number of priority risks, the number of target behaviors, and the number of intended pathways.

For each model, across all its intended pathways, we calculated the mean number of technique categories the model required, recommended, endorsed (the sum of required and recommended), not endorsed but compatible, and rated as not compatible with the model. To describe variability within models, we calculated the standard deviation of the number of technique categories endorsed, not endorsed but compatible, and not compatible among its intended pathways.

We explored within-model consistency in endorsement of technique categories across intended pathways with the same priority risk but different target behaviors and across intended pathways with the same target behavior but different priority risks. We used three indicators of consistency: 1) same set of endorsed technique categories; 2) same set of high-emphasis technique categories; and 3) same pattern of emphasis across of technique categories. For each model, we calculated the percentage of intended pathways in which the indicator was present.

\section{Discussion and Interpretation of Results}

HARC coordinating center investigators prepared results tables and talking points for three rounds of independent review and written feedback by model representatives followed by group discussion of the collated feedback.

\section{Results}

\section{Participating Home Visiting Models}

All five models aim to promote good birth outcomes as well as a broad range of other outcomes, but they vary in enrollment eligibility criteria, educational requirements for hire as home visitors, and theories of change (Table 2). In general, years of dissemination was positively associated with number of local implementing agencies. 


\section{Models' Priority Risks}

Each risk was designated as a priority risk by at least four models (Table 3). All models made it a high priority to reduce high stress. All five prioritized reducing inadequate prenatal care, maternal depression, intimate partner violence, tobacco use and alcohol use, but some rated these as a moderate versus high priority. Four models rated reducing illicit substance use as a high priority. Women known to use illicit substances were not eligible for enrolling in the other model and thus this was not a priority risk for that model. Each biologic risk was a priority risk for four models, though not the same four models. Biologic risks were not a high priority for most models.

\section{Models' Intended Pathways to Good Birth Outcomes}

Each of the 41 pathways was an intended pathway for at least one model (Figure 3). Pathways involving basic health promotion behaviors were always designated as intended pathways. Adhering to the prenatal care visit schedule was more often a part of intended pathways than was alerting the prenatal care provider to observed warning signs.

Pathways involving reducing tobacco or alcohol use were more likely to be designated as intended pathways if the intent was to reduce the risks of diabetes and high blood pressure rather than the risks of these behaviors themselves. Condom use was part of an intended pathway for all models that designated infection as a priority risk. Models were less likely to designate safety plans, medication adherence and self-monitoring of physiologic indicators as part of intended pathways.

\section{Models' Stance on Technique Categories}

Table 4 summarizes models' stance regarding use of technique categories. Across all models combined, 11 technique categories were endorsed in $\geq 75 \%$ of intended pathways and eight were endorsed in $50-74 \%$ of intended pathways.

Technique categories were rarely judged not compatible with a home visiting model. Only four technique categories were ever rated as not compatible. Of these, only scheduled consequences and self-identity were rated as not compatible in a quarter or more of intended pathways. Even the least favored technique category - scheduled consequences - was endorsed for a few intended pathways.

\section{Models' Stance on the Relative Emphasis to Give Technique Categories}

Four models designated some technique categories as high-emphasis in some intended pathways while one model did not designate any category as high-emphasis in any intended pathway. Referral and linkage was designated as high-emphasis by all four of these models, while all other techniques were so designated by three or fewer models (Table 4, last column).

Figure 4 illustrates more detailed results for four intended pathways to reduce maternal depression. The number of models endorsing specific technique categories and the number designating a category as high-emphasis was similar across the four target behaviors. Family referral to and linkage with community resources was the only technique category that all four models designated as a high-emphasis technique category across all four pathways. Five technique categories were endorsed by all four models across all four pathways, but designated as high-emphasis by only some models. Models' varied greatly in their stance on several technique categories. Self-identity, for example, was consistently designated as high emphasis by one model, but not endorsed at all by other models on three intended pathways.

\section{Cross-model Similarities and Differences}

Table 5 gives descriptive statistics to characterize the models as a group and to highlight similarities and differences among them. On average, models aimed to reduce 9.2 of the 10 risks by promoting 11.2 of the 14 behaviors, specifying 31.6 of the 41 pathways as intended pathways. But models varied greatly on each indicator. For example, they ranged from 16 to 41 in their number of intended pathways to achieve good birth outcomes.

On average, models endorsed 13.8 technique categories per intended pathway, rated another 8.0 technique categories as compatible though not endorsed, and rated 1.2 technique categories as not compatible. Cross-model differences in rating technique categories were more of degree than of kind. Models differed in the number of technique categories they endorsed and

Page $7 / 24$ 
in whether their endorsement was in the form of a requirement versus a recommendation (Table 5, italicized text). Yet models were similar in rating very few technique categories as not compatible with their approach. In short, models found nearly all technique categories to be compatible, differing only in whether they explicitly endorsed a technique and in the level of endorsement.

Models differed in how consistent they were in the number of technique categories they endorsed across their intended pathways. The smallest model-specific standard deviation was 0.0 , reflecting complete consistency in the number of technique categories a model endorsed across its intended pathways. In contrast, the model with a standard deviation of 5.3 endorsed as few as seven and as many as 22 technique categories across its intended pathways. Models were similar with one another and internally consistent across their intended pathways in the number of technique categories they judged to be incompatible with their philosophy and approach.

The bottom panel of Table 5 focuses on consistency in the specific technique categories that models endorsed. On average, models endorsed the same technique categories about a third of the time on intended pathways with the same priority risk but different target behaviors. This was true as well for the technique categories designated as high-emphasis. However, when considering all five emphasis ratings, intended pathways rarely exhibited the same pattern of emphasis for the technique categories they had in common. These indicators of consistency varied greatly across models.

Consistency was greater across intended pathways with the same target behavior but different priority risks. On average, models specified the same high-emphasis technique categories about two-thirds of the time, and the same pattern of emphasis of common technique categories about half the time. These indicators of consistency varied substantially across models.

\section{Discussion}

Home visiting is building a new research paradigm to achieve greater precision. Reasons include the legislative mandate to individualize services; ${ }^{1}$ empirical evidence that family engagement has remained challenging ${ }^{5}$ and that average effects have remained small over many years; ${ }^{6,7}$ and the conclusion of systematic reviews and meta-analytic research that past research methods and reporting practices seriously compromise the ability to identify core components. ${ }^{8} \mathrm{~A}$ shift toward precision also aligns with shifts toward precision in health care ${ }^{32}$ and public health ${ }^{33}$ in general.

The new research paradigm requires not only innovative study designs ${ }^{34}$ but also a common over-arching conceptual framework and language to support shared learning. Lack of a common framework and language yield unclear, inconsistent descriptions of interventions, frustrating what can be learned from systematic reviews and meta-analytic studies. This is true for home visiting per $\mathrm{se}^{8,35}$ and also for interventions that can be implemented in a range of settings, for example to promote behavioral health ${ }^{16}$ and positive parenting behavior. ${ }^{36}$ Even more important for home visiting's evolution, lack of a common over-arching conceptual framework and language could hamper stakeholders' collaboration in developing clear, coherent, effective interventions.

Evidence-based models play a critical role in shifting the research paradigm because they are a part of the context for defining and testing existing and emerging interventions. This study confirmed the feasibility of using a standardized approach to elicit models' intended behavioral pathways and their stance on techniques to support families' progress on those pathways. To our knowledge, this is the first home visiting study to use this approach. Results have implications for future research, policy and practice to promote precision in home visiting.

Models identified a large number of intended pathways involving diverse priority risks and target behaviors. This suggests that researchers designing new interventions for implementation within existing home visiting models must be aware of the fit of such interventions with models' priority risks and target behaviors. It also speaks to the complexity of home visiting, the need for valid and reliable tools to assess risks and changes in target behaviors, and the potential value of prioritizing intended pathways.

Emerging research funding opportunities for innovation toward precision home visiting ${ }^{37,38}$ make clear the growing need for a common framework and language not only to specify the innovations, but also to define and differentiate the context of the home visiting models in which they are intended to be implemented.

While models differed on their mix of intended pathways, it is premature to suggest whether and how to triage families across models based on this aspect of model differentiation. Many communities offer only one model, and triage policies must consider

Page $8 / 24$ 
many factors beyond models' intended pathways.

Models ranged from 1.5 to 20.0 in the average number of technique categories they endorsed across their intended pathways. This variation might reflect philosophical differences across models on prescribing the techniques that visitors are to use versus delegating prescription of techniques to implementing agencies. For models that delegate, research is needed to learn how implementing agencies decide which techniques to endorse. For all models, it is important to ascertain how clearly model expectations are communicated to implementing agencies and how adequately implementation systems support staff to use expected techniques.

Model representatives rated nearly all behavior change technique categories as compatible with their models. This suggests that intervention developers could draw from a broad portfolio of techniques in designing interventions compatible with existing evidence-based models.

Models varied in the consistency of their expectations for using and emphasizing techniques across intended pathways. Some models had consistent expectations across all pathways. For such models, results for one pathway might be generalizable to other pathways. For all models combined, consistency was greater in subsets of pathways with a common target behavior than with a common risk. On the one hand, this suggests it might be possible to focus on target behaviors rather than intended pathways. Still, some models' survey data showed no consistency across intended pathways with a common behavior. Qualitative work is needed to learn the reasons for and implications of model differences in the consistency of expectations across intended pathways.

Several study limitations should be addressed in future work. The project considered only prenatal home visiting to promote good birth outcomes and focused only on intended pathways and intervention techniques. Parallel work is needed for home visiting's other intended outcomes. For all outcomes, complementary work is needed to identify models' underlying theories of behavior change, expected links from techniques to mechanisms of action, and how such links might be moderated by context. Many of the underlying theories of home visiting are explanatory theories rather than theories of behavior change; future work needs to specify underlying theory in terms of mechanisms of action and mediating target behaviors.

The project's operationalization of intervention techniques was limited in several ways. We used technique categories rather than individual techniques to reduce respondent burden; future work should investigate the value of focusing on individual techniques. We drew from a highly regarded taxonomy of behavior change techniques, but had to add several categories for techniques commonly used in home visiting such as referral, coordination, and assessing readiness for change. Rigorous developmental work is underway to refine these categories.

The project was limited in focusing much more on content-based than relational techniques. Content-based techniques reflect what is delivered while relational techniques reflect how it is delivered. Home visiting has always valued the importance of a strong working relationship between family and home visitor. This argues for incorporating relational techniques such as those of motivational interviewing ${ }^{15}$ and of communication strategies to achieve the social-emotional and activation functions of social interaction. ${ }^{16,39,40,41,42}$ In debriefing, models considered the distinction between techniques to establish a working relationship and the relationship itself. They agreed on the critical need for research to confirm the influence of relational links with the building of a strong working relationship, and to test the working relationship itself as a mediator of behavior change.

In debriefing, model representatives also considered methodologic issues regarding the designation of target behaviors and technique categories as "required" from "recommended". They shared the process each had used to determine their model's stance. They discussed their models' mechanisms to communicate expectations to local implementing agencies, for example through training, curricula and the credentialing process. They discussed implications of the distinction between a requirement and a recommendation for implementation systems and local program operations. Discussion revealed the need to distinguish model expectations per se from mechanisms to convey expectations to local programs and to support staff to meet them.

The work reported here demonstrated the feasibility of defining models' intended pathways and stance on behavior change techniques. Two complementary aspects of the project are now nearing completion. The first of these, a survey of local programs, assesses local programs' perspectives on intended pathways and technique categories and the strength of current implementation 
systems to support their home visitors' effective use of these techniques. The second aspect, qualitative interviews with expectant women enrolled in home visiting, elicits their perspectives on the behavior change techniques used by their home visitors.

Beyond this project, HARC brings stakeholders together to build the Precision Paradigm to support research on high priority issues such as:

- The coherence of interventions as indicated by defining intervention techniques, mechanisms of action, and target behaviors in alignment with family assets, needs, interests and concerns in pursuing intended outcomes.

- The clarity of interventions as indicated by the concordance of home visitors' perceptions with models' and implementing agencies' expectations regarding intended pathways and intervention techniques.

- The adequacy of implementation systems to motivate, enable and reinforce home visitors' competent use of intervention techniques.

- Identification of intervention techniques in models using more of a psychosocial than a behavioral approach to achieving intended outcomes.

- How techniques are combined into interventions, and how relational and content techniques work together to promote behavior change.

- The influence of interventions on presumed mechanisms of action for target behaviors and how context moderates this. Prior research suggests that evidence of the links between techniques and mechanisms of action is far from definitive. ${ }^{43}$

- How family and community context moderates the acceptability and effectiveness of specific techniques.

The models that participated in this project are exemplars for other stakeholders whose perspectives are also critical in innovation toward precision home visiting. HARC's coordinating center is working with diverse stakeholder groups to build the Precision Paradigm and promote its use in innovative research toward precision home visiting. Model representatives strongly endorsed qualitative approaches to complement the quantitative approach used in this project. They strongly endorsed as well HARC's plan to mine the wisdom and culture of the families who enroll in home visiting and the home visitors who provide services as reflected in the paradigm's reliance on home visiting experience to complement theory and empirical evidence.

To accelerate this work, HARC makes the resources developed publicly available via its website, ${ }^{19}$ technical assistance to stakeholder teams, and Open Science publication.

\section{Conclusions}

Evidence-based home visiting models articulated their intended pathways to good birth outcomes and their expectations for home visitors' use of behavior change techniques to promote families' progress on these behavioral pathways. The Precision Paradigm is a promising resource to accelerate innovative cross-model research to clarify which interventions within home visiting work best for which families, in which contexts, why and how.

\section{List Of Abbreviations}




\begin{tabular}{|ll|}
\hline EBHV & Evidence-based home visiting \\
\hline HARC & Home Visiting Applied Research Collaborative \\
HFA & Healthy Families America \\
\hline HomVEE & Home Visiting Evidence of Effectiveness \\
\hline IPV & Intimate partner violence \\
\hline LIA & Local implementing agency \\
\hline MIECHV Program & Maternal, Infant and Early Childhood Home Visiting Program \\
\hline NFP & Nurse Family Partnership \\
\hline PNC & Prenatal care \\
\hline SU & Substance use \\
\hline
\end{tabular}

\section{Declarations}

\section{Ethics Approval and Consent to Participate}

Not applicable.

\section{Consent for Publication}

Not applicable.

\section{Availability of Data and Materials}

The datasets generated and analyzed during the current study are not publicly available due to the proprietary nature of the national home visiting models.

\section{Competing Interests}

The authors declare that they have no competing interests.

\section{Funding}

This project was funded by a grant from the Pritzker Children's Initiative (Grant 134163). It was carried out under the auspices of the Home Visiting Applied Research Collaborative (HARC), whose core operations are supported by the Health Resources and Services Administration (HRSA) of the U.S. Department of Health and Human Services (HHS) under cooperative agreement UD5MC30792, Maternal, Infant and Early Childhood Home Visiting Research and Development Platform. The content and conclusions of this manuscript are those of the authors and should not be construed as the official position or policy of, nor should any endorsements be inferred by HRSA, HHS or the U.S. Government.

\section{Authors' Contributions}

$\mathrm{AKD}, \mathrm{KMB}, \mathrm{CZ}, \mathrm{KO}$ and $\mathrm{DD}$ contributed to the overall conception and design of the study. AKD, KMB, CZ, KO, KH, Al, AK, CM and WT made substantial contributions to data acquisition. AKD and $C Z$ conducted data analysis. All authors interpreted study results. AKD, KMB, CZ and KO drafted the manuscript. AKD, KMB, CZ, DD, KH, Al, AK, CM and WT made substantive revisions to the manuscript. All authors read and approved the final manuscript.

\section{Acknowledgements}

The authors wish to thank contributions of model leadership and staff who assisted in providing project data and/or feedback on drafts of the manuscript. They include: Arietta Slade, PhD and Lois Sadler, PhD, RN, FAAN, co-founders of Minding the Baby; Kit 
Patterson, Senior Director of Training and Technical Assistance, Healthy Families America at Prevent Child Abuse America; Elly Yost, RN, MSN, MBA/MHA, Director of Nursing Initiatives, Nurse-Family Partnership; and Melissa Heibel, MSN, RN, Implementation Specialist - Nurse Consultant, Nurse-Family Partnership. The authors also thank HARC Coordinating Center staff Danielle Gaskin, Paris Lowe, and R. Morgan Taylor for assisting with development of data collection instruments and processing of study data.

\section{References}

1. Maternal, Infant, and Early Childhood Home Visiting Program 75 Fed. Reg. 43,172; 2010 Jul 23. Available from: https://www.federalregister.gov/documents/2010/07/23/2010-18013/maternal-infant-and-early-childhood-home-visitingprogram

2. Bipartisan Budget Act of 2018, 1892 USC $\S 50601-50607 ; 2018$. Available from: https://www.congress.gov/115/plaws/publ123/PLAW-115publ123.pdf

3. Home Visiting Evidence of Effectiveness. Evidence-based Models Eligible to Maternal, Infant, and Early Childhood Home Visiting (MIECHV) Grantees. U.S. Department of Health and Human Services; 2020. Available from: https://homvee.acf.hhs.gov/HRSA-Models-Eligible-MIECHV-Grantees

4. Maternal, Infant and Early Childhood Home Visiting Program Orientation Guide. 2020 Feb. Available from: https://mchb.hrsa.gov/sites/default/files/mchb/MaternalChildHealthlnitiatives/HomeVisiting/miechv-orientation-guide.pdf

5. Duggan A, Portilla XA, Filene JH, Crowne SS, Hill CJ, Lee H, et al. Implementation of Evidence-Based Early Childhood Home Visiting: Results from the Mother and Infant Home Visiting Program Evaluation. Washington, DC: Office of Planning, Research, and Evaluation, Administration for Children and Families, U.S. Department of Health and Human Services; 2018. 378 p. OPRE Report: 2018-76A.

6. Michalopoulos C, Faucetta K, Hill C, Portilla X, Burrell L, Lee H, et al. Impacts on Family Outcomes of Evidence-Based Early Childhood Home Visiting: Results from the Mother and Infant Home Visiting Program Evaluation. Washington, DC: Office of Planning, Research, and Evaluation, Administration for Children and Families, U.S. Department of Health and Human Services; 2019 Jan. OPRE Report: 2019-07.

7. Lee H, Crowne SS, Estarziau M, Kranker K, Michalopoulos C, Warren A, et al. The Effects of Home Visiting on Prenatal Health, Birth Outcomes, and Health Care Use in the First Year of Life: Final Implementation and Impact Findings from the Mother and Infant Home Visiting Program Evaluation-Strong Start. Washington, DC: Office of Planning, Research, and Evaluation, Administration for Children and Families, U.S. Department of Health and Human Services; 2019. OPRE Report 2019-08.

8. Filene JH, Kaminski JW, Valle LA, Cachat P. Components associated with home visiting program outcomes: a meta-analysis. Pediatrics. 2013 Nov 1;132(2):S100-9.

9. Supplee L, Ammerman RT, Duggan A, List JA, Suskind D. The role of open science practices in scaling evidence-based prevention programs. Prev Sci. Invited/under review.

10. Duggan A, Jones-Harden B, Kemner A, Pillow-Price K. Innovation toward Precision Home Visiting. Plenary Presentation at the National Summit on Quality in Home Visiting; 2019 Jan 31; Washington, DC.

11. Supplee L, Duggan A. Innovative Research Methods to Advance Precision in Home Visiting for More Efficient and Effective Programs. Child Dev Perspect. 2019 Sep;13(3):173-9.

12. Petticrew M. When are complex interventions 'complex'? When are simple interventions 'simple'? Eur J Public Health 2011;21(4):597-598.

13. Chorpita BF, Daleiden EL, Weisz JR. Identifying and selecting the common elements of evidence based interventions: A distillation and matching model. Mental Health Serv Res. 2005b;7:5-20.

14. Tate DF, Lytle LA, Sherwood NE, Haire-Joshu D, Matheson D, Moore SM, Loria CM, Pratt C, Ward DS, Belle SH, Michie S. Deconstructing interventions: approaches to studying behavior change techniques across obesity interventions. TBM. 2016 Jun;6(2):236-243.

15. Hardcastle SJ, Fortier M, Blake N, Hagger MS. Identifying content-based and relational techniques to change behaviour in motivational Interviewing. Health Psychol Rev. 2017;11(1):1-16. 
16. Roter D, Larson S. The Roter Interaction Analysis System (RIAS): Utility and Flexibility for Analysis of Medical Interactions. Patient Educ Couns. 2002;46(4): 243-251.

17. Michie S, Richardson M, Johnston M, Abraham C, Francis J, Hardeman W, et al. The behavior change technique taxonomy (v1) of 93 hierarchically clustered techniques: building an international consensus for the reporting of behavior change interventions. Ann Behav Med. 2013 Aug 1;46(1):81-95.

18. Kok G, Gottlieb NH, Peters GJY, Mullen PD, Parcel GS, Ruiter RAC, et al. A taxonomy of behaviour change methods: an Intervention Mapping approach. Health Psychol Rev. 2016;10(3):297-312.

19. Home Visiting Applied Research Collaborative. 2020. Available from: http://www.hvresearch.org

20. Duggan A, Minkovitz C, Chaffin M, Korfmacher J, Brooks-Gunn J, Crowne S, et al. Creating a National Home Visiting Research Network. Pediatrics. 2013 Nov;132(2):S82-9.

21. Human Behaviour Change Project. 2021. Available from: https://www.humanbehaviourchange.org/

22. von Elm E, Altman DG, Egger M, Pocock SJ, Gøtzsche PC, Vandenbroucke JP; STROBE Initiative. Strengthening the Reporting of Observational Studies in Epidemiology (STROBE) statement: guidelines for reporting observational studies. BMJ. 2007 Oct 20;335(7624):806-8.

23. Centers for Disease Control and Prevention (CDC), Division of Reproductive Health, National Center for Chronic Disease Prevention and Health Promotion. Preterm Birth. 2020 Oct 30. Available from: https://www.cdc.gov/reproductivehealth/maternalinfanthealth/pretermbirth.htm

24. The American College of Obstetricians and Gynecologists (ACOG), Committee on Practice Bulletins - Obstetrics. Practice bulletin no. 130: Prediction and prevention of preterm birth. Obstet Gynecol. 2012 Oct;120(4): 964-73.

25. March of Dimes. Low Birthweight. 2018 Mar. Available from: https://www.marchofdimes.org/complications/lowbirthweight.aspx

26. March of Dimes. Preterm labor and premature birth: Are you at risk? 2018 Mar. Available from: https://www.marchofdimes.org/complications/preterm-labor-and-premature-birth-are-you-at-risk.aspx

27. Robinson JN, Norwitz ER. Preterm birth: Risk factors, interventions for risk reduction, and maternal prognosis. 2021. In UpToDate. Lockwood, C.J. \& Barss, V.A. (Eds.): UpToDate Inc. Available from: https://www.uptodate.com/contents/pretermbirth-risk-factors-interventions-for-risk-reduction-and-maternal-prognosis? search=preterm\%20birth\&source=search_result\&selectedTitle=1 150\&usage_type=default\&display_rank=1

28. American College of Obstetrics and Gynecologists Clinical Guidance: Committee Opinions. 2021. Available from: https://www.acog.org/clinical/clinical-guidance/committee-opinion

29. Glanz K, Rimer BK, Viswanath K. Health Behavior and Health Education: Theory, Research, and Practice. 4th ed. Jossey-Bass Public Health; 2008. Chapter 2, Theory, Research, and Practice in Health Behavior; p. 23-42.

30. West A, Duggan AK, Gruss K, Minkovitz CS. Creating a measurement framework for service coordination in maternal and early childhood home visiting: An evidence-informed, expert process. Child Youth Serv Rev. 2018 Jun 1;89:289-97.

31. Smith JD, Berkel C, Rudo-Stern J, Montaño Z, St George SM, Prado G, et al. The Family Check-Up 4 Health (FCU4Health): Applying Implementation Science Frameworks to the Process of Adapting an Evidence-Based Parenting Program for Prevention of Pediatric Obesity and Excess Weight Gain in Primary Care. Front Public Health. 2018 Oct 15; 6:293.

32. Collins FS, Varmus H. A new initiative on precision medicine. N Engl J Med. 2015;372(9):793-95.

33. Khoury MJ, lademarco MF, Riley WT. Precision Public Health for the Era of Precision Medicine. Am J Prev Med. 2016;50(3):398-401.

34. Home Visiting Applied Research Collaborative. 2018 Methods Meeting. 2018 Apr. Available from: https://www.hvresearch.org/about/presentations/2018-methods-meeting/.

35. Sweet MA, Appelbaum MI. Is home visiting an effective strategy? A meta-analytic review of home visiting programs for families with young children. Child Dev. 2004;75(5):1435-56.

36. Hamby CM, Lunkenheimer ES, Fisher PA. The potential of video feedback interventions to improve parent-child interaction skills in parents with intellectual disability. Child Youth Serv Rev. 2019;105:104395. 
37. Notice of Intent to Publish a Funding Opportunity Announcement for Early Intervention to Promote Cardiovascular Health of Mothers and Children (ENRICH) Multisite (UG3/UH3) with Coordinating Center (U24). National Heart, Lung, and Blood Institute. 27 Oct 2020. Notice No.: NOT-HL-20-820. Available from: https://grants.nih.gov/grants/guide/notice-files/NOT-HL-20-820.html

38. Health Resources and Services Administration. Evaluator Community of Practice \#13: A Conversation with HRSA on Coordinated State Evaluation. 2020 Sep 9.

39. Bales, Robert F. Interaction Process Analysis: A Method for the Study of Small Groups. Cambridge, MA: Addison-Wesley Press, Inc; 1950. 203 p.

40. Del Piccolo L, de Haes H, Heaven C, Jansen J, Verheul W, Bensing J, et al. Development of the Verona Coding Definitions of Emotional Sequences to code health providers' responses (VR-CoDES-P) to patient cues and concerns. Patient Educ Couns. 2011; 82: 149-155.

41. Korfmacher J, West A, Sparr M, Frese M. Responsive Partnerships with Families: Results from Piloting a Home Visitor Communication Toolkit. Workshop at the 9th National Summit on Quality in Home Visiting Programs; 2020 Jan 30; Washington, DC.

42. Institute for the Advancement of Family Support Professionals. 2020. Available from: https://Institutefsp.Org/About.

43. Carey RN, Connell LE, Johnston M, Rothman AJ, de Bruin M, Kelly MP, et al. Behavior Change Techniques and Their Mechanisms of Action: A Synthesis of Links Described in Published Intervention Literature. Ann Behav Med. 2019;53:693-707.

44. National Home Visiting Resource Center. 2019 Home Visiting Yearbook. Arlington, VA: James Bell Associates and the Urban Institute; 2019. Available from: https://nhvrc.org/yearbook/2019-yearbook/

\section{Tables}


Table 1

Scope of Survey 1: Potential Pathways to Promote Good Birth Outcomes ${ }^{1}$

\begin{tabular}{|c|c|c|c|c|c|c|c|c|c|c|}
\hline \multirow{2}{*}{$\begin{array}{l} \\
\text { Target } \\
\text { Maternal } \\
\text { Behaviors }\end{array}$} & \multirow{2}{*}{$\begin{array}{l}\text { Health } \\
\text { Care Risk } \\
\text { Inadequate } \\
\text { PNC }^{2}\end{array}$} & \multicolumn{2}{|c|}{$\begin{array}{l}\text { Psychological } \\
\text { Risks }\end{array}$} & \multirow[b]{2}{*}{ IPV $^{3}$} & \multicolumn{3}{|c|}{ Behavioral Health Risks } & \multicolumn{3}{|l|}{$\begin{array}{l}\text { Biologic } \\
\text { Risks }\end{array}$} \\
\hline & & $\begin{array}{l}\text { High } \\
\text { Stress }\end{array}$ & Depression & & $\begin{array}{l}\text { Tobacco } \\
\text { Use }\end{array}$ & $\begin{array}{l}\text { Alcohol } \\
\text { Use }\end{array}$ & $\begin{array}{l}\text { Illicit } \\
\text { su }^{4}\end{array}$ & Infection ${ }^{5}$ & Diabetes & $\begin{array}{l}\text { High } \\
\text { Blood } \\
\text { Pressure }\end{array}$ \\
\hline \multicolumn{11}{|l|}{$\begin{array}{l}\text { Basic } \\
\text { Health } \\
\text { Promotion }\end{array}$} \\
\hline $\begin{array}{l}\text { Engage in } \\
\text { physical } \\
\text { activity }\end{array}$ & & $x$ & $\mathrm{X}$ & & & & & & $\mathrm{X}$ & $x$ \\
\hline $\begin{array}{l}\text { Adhere to a } \\
\text { healthy } \\
\text { diet }\end{array}$ & & & & & & & & & $x$ & $x$ \\
\hline $\begin{array}{l}\text { Engage in } \\
\text { stress } \\
\text { reduction } \\
\text { activities }\end{array}$ & & $x$ & $x$ & $\mathrm{x}$ & $x$ & $x$ & $x$ & & & \\
\hline $\begin{array}{l}\text { Use social } \\
\text { supports }\end{array}$ & & $x$ & $x$ & $\mathrm{x}$ & $x$ & $x$ & $\mathrm{x}$ & & & \\
\hline \multicolumn{11}{|l|}{$\begin{array}{l}\text { Health } \\
\text { Care Use }\end{array}$} \\
\hline $\begin{array}{l}\text { Adhere to } \\
\text { PNC visit } \\
\text { schedule }\end{array}$ & $x$ & & $\mathrm{x}$ & & & & & & $x$ & $x$ \\
\hline $\begin{array}{l}\text { Engage in } \\
\text { SU } \\
\text { treatment }\end{array}$ & & & & & & & $\mathrm{x}$ & & & \\
\hline \multicolumn{11}{|l|}{$\begin{array}{l}\text { Behavioral } \\
\text { Health }\end{array}$} \\
\hline $\begin{array}{l}\text { Stop or } \\
\text { reduce } \\
\text { tobacco } \\
\text { use }\end{array}$ & & & & & $\mathrm{x}$ & & & & & $x$ \\
\hline $\begin{array}{l}\text { Stop or } \\
\text { reduce } \\
\text { alcohol use }\end{array}$ & & & & & & $x$ & & & & $x$ \\
\hline $\begin{array}{l}\text { Stop or } \\
\text { reduce } \\
\text { illicit SU }\end{array}$ & & & & & & & $x$ & & & \\
\hline \multicolumn{11}{|l|}{$\begin{array}{l}\text { Specific } \\
\text { Risk } \\
\text { Reduction } \\
\text { Behaviors }\end{array}$} \\
\hline $\begin{array}{l}\text { Use } \\
\text { condoms }\end{array}$ & & & & & & & & $x$ & & \\
\hline $\begin{array}{l}\text { Develop a } \\
\text { safety plan }\end{array}$ & & & & $x$ & & & & & & \\
\hline $\begin{array}{l}\text { Alert PNC } \\
\text { provider to } \\
\text { warning } \\
\text { signs }\end{array}$ & & & $x$ & & & & & & $x$ & $x$ \\
\hline
\end{tabular}


monitor

physiologic

indicators

${ }^{1}$ Each $\mathrm{X}$ represents a unique pathway to good birth outcomes by promoting a specific target behavior to reduce a specific risk contributing to poor birth outcomes. There are 41 pathways.

${ }^{2}$ Inadequate prenatal care is defined as late entry or inadequate number of visits post enrollment in HV.

${ }^{3}$ Intimate partner violence

${ }^{4}$ Substance use (heroin or cocaine)

${ }^{5}$ Sexually transmitted, vaginal, or urinary tract

Table 2

Characteristics of Participating Home Visiting Models

\begin{tabular}{|c|c|c|c|c|c|c|}
\hline & $\begin{array}{l}\text { Year } \\
\text { Designated } \\
\text { as EBHV }{ }^{1}\end{array}$ & $\begin{array}{l}\text { Eligibility for } \\
\text { Enrollment }\end{array}$ & $\begin{array}{l}\text { Home Visitor } \\
\text { Educational } \\
\text { Requirements for Hire }\end{array}$ & $\begin{array}{l}\text { Underlying Theories } \\
\text { or Frameworks }\end{array}$ & $\begin{array}{l}\text { Year } \\
\text { Scale } \\
\text { Up } \\
\text { Began }\end{array}$ & $\begin{array}{l}\text { Number } \\
\text { of } \\
\text { LIAs }^{2}\end{array}$ \\
\hline $\begin{array}{l}\text { Family } \\
\text { Spirit }\end{array}$ & 2015 & $\begin{array}{l}\text { Expectant women and } \\
\text { families with children } \\
<3 \text { years old }\end{array}$ & $\begin{array}{l}\text { Paraprofessional health } \\
\text { educators with at least a } \\
\text { high school credential }\end{array}$ & $\begin{array}{l}\text { G.R. Patterson's } \\
\text { developmental } \\
\text { model; Traditional } \\
\text { Tribal Teachings }\end{array}$ & 2006 & 54 \\
\hline $\begin{array}{l}\text { Healthy } \\
\text { Families } \\
\text { America }\end{array}$ & 2011 & $\begin{array}{l}\text { Expectant women and } \\
\text { families with } \\
\text { newborns. HFA sites } \\
\text { determine additional } \\
\text { eligibility criteria }\end{array}$ & $\begin{array}{l}\text { Home visitors with at } \\
\text { least a high school } \\
\text { diploma or bachelor's } \\
\text { degree, depending on } \\
\text { state or agency needs }\end{array}$ & $\begin{array}{l}\text { Attachment theory; } \\
\text { Bio-ecological } \\
\text { systems theories; } \\
\text { Dyadic; Trauma- } \\
\text { Informed Care; } \\
\text { Strength } \\
\text { Based/Adaptive }\end{array}$ & 1992 & 574 \\
\hline $\begin{array}{l}\text { Minding } \\
\text { the Baby }\end{array}$ & 2014 & $\begin{array}{l}\text { First-time expectant } \\
\text { women in their } 2 \text { nd or } \\
\text { 3rd trimester of } \\
\text { pregnancy }\end{array}$ & $\begin{array}{l}\text { Nurse or mental health } \\
\text { professionals. Mental } \\
\text { health visitors must } \\
\text { have a master's in social } \\
\text { work or a related field }\end{array}$ & $\begin{array}{l}\text { Attachment theory; } \\
\text { Reflective parenting; } \\
\text { Self-efficacy; Social- } \\
\text { Ecological }\end{array}$ & 2002 & 4 \\
\hline $\begin{array}{l}\text { Nurse- } \\
\text { Family } \\
\text { Partnership }\end{array}$ & 2011 & $\begin{array}{l}\text { First-time expectant } \\
\text { women in } 1 \text { st or } 2 \text { nd } \\
\text { trimester of pregnancy } \\
\text { with low-income. NFP } \\
\text { sites determine } \\
\text { additional eligibility } \\
\text { criteria. }\end{array}$ & $\begin{array}{l}\text { Nurses with at least a } \\
\text { bachelor's degree }\end{array}$ & $\begin{array}{l}\text { Attachment theory; } \\
\text { Human Ecology } \\
\text { theory; Self-Efficacy; } \\
\text { Social-Cognitive }\end{array}$ & 1996 & 312 \\
\hline $\begin{array}{l}\text { Parents as } \\
\text { Teachers }\end{array}$ & 2011 & $\begin{array}{l}\text { Expectant women and } \\
\text { families with children } \\
\text { up to kindergarten } \\
\text { entry } \\
\text { (usually age 5) }\end{array}$ & $\begin{array}{l}\text { Paraprofessional parent } \\
\text { educators with at least a } \\
\text { high school credential; } \\
\text { bachelor's degree in } \\
\text { early child education } \\
\text { recommended }\end{array}$ & $\begin{array}{l}\text { Attribution theory; } \\
\text { Developmental } \\
\text { Parenting; Family } \\
\text { Systems Theory; } \\
\text { Human Ecology } \\
\text { Theory }\end{array}$ & 1985 & 987 \\
\hline
\end{tabular}


Table 3

Cross-Model ${ }^{1}$ Distribution of Responses regarding Priority Given to Reducing Specific Risks

\begin{tabular}{|c|c|c|c|c|c|}
\hline Risk Category & Specific Risk & High Priority & Moderate Priority & Low Priority & Not a Priority \\
\hline Health care risk & Inadequate prenatal care & 4 & 1 & & \\
\hline \multirow[t]{3}{*}{ Psychosocial risks } & High stress & 5 & & & \\
\hline & Depression & 4 & 1 & & \\
\hline & Intimate partner violence & 3 & 2 & & \\
\hline \multirow[t]{3}{*}{ Behavioral health risks } & Tobacco use & 3 & 2 & & \\
\hline & Alcohol use & 4 & 1 & & \\
\hline & Illicit substance use & 4 & & & 1 \\
\hline \multirow[t]{3}{*}{ Biologic risks } & Infection & 2 & 1 & 1 & 1 \\
\hline & Diabetes & 2 & 2 & & 1 \\
\hline & High blood pressure & 1 & 2 & 1 & 1 \\
\hline
\end{tabular}


Table 4

Cross-Model Distribution of Expectations for Visitors' Use of Specific Technique Categories in Intended Pathways ${ }^{1}$ to Good Birth Outcomes

\begin{tabular}{|c|c|c|c|c|c|c|c|}
\hline $\begin{array}{l}\text { How Often } \\
\text { Technique } \\
\text { Category is } \\
\text { Endorsed }^{2}\end{array}$ & \multicolumn{2}{|c|}{$\begin{array}{l}\text { Technique Number and } \\
\text { Name }^{3}\end{array}$} & Required & Recommended & $\begin{array}{l}\text { No } \\
\text { Expectation } \\
\text { but } \\
\text { Compatible }\end{array}$ & $\begin{array}{l}\text { Not } \\
\text { Compatible }\end{array}$ & $\begin{array}{l}\text { Models } \\
\text { Designating } \\
\text { as High- } \\
\text { Emphasis }^{4}\end{array}$ \\
\hline \multirow{11}{*}{$\begin{array}{l}\geq 75 \% \text { of intended } \\
\text { pathways }\end{array}$} & T20 & Self-Belief & $42 \%$ & $42 \%$ & $16 \%$ & $0 \%$ & 3 \\
\hline & T03 & $\begin{array}{l}\text { Monitoring and } \\
\text { Feedback }\end{array}$ & $37 \%$ & $48 \%$ & $15 \%$ & $0 \%$ & 3 \\
\hline & T22 & $\begin{array}{l}\text { Monitoring and } \\
\text { Follow-up of } \\
\text { Referral }\end{array}$ & $35 \%$ & $56 \%$ & $9 \%$ & $0 \%$ & 3 \\
\hline & $\mathrm{T} 21$ & $\begin{array}{l}\text { Referral and } \\
\text { Linkage }\end{array}$ & $32 \%$ & $59 \%$ & $9 \%$ & $0 \%$ & 4 \\
\hline & T01 & $\begin{array}{l}\text { Assess Readiness } \\
\text { for Change }\end{array}$ & $30 \%$ & $49 \%$ & $21 \%$ & $0 \%$ & 1 \\
\hline & T14 & Credible Source & $27 \%$ & $63 \%$ & $10 \%$ & $0 \%$ & 3 \\
\hline & T23 & $\begin{array}{l}\text { Coordination with } \\
\text { Other Services }\end{array}$ & $18 \%$ & $73 \%$ & $9 \%$ & $0 \%$ & 3 \\
\hline & T02 & Goals and Planning & $16 \%$ & $73 \%$ & $11 \%$ & $0 \%$ & 2 \\
\hline & T04 & $\begin{array}{l}\text { Provide Social } \\
\text { Support }\end{array}$ & $15 \%$ & $72 \%$ & $13 \%$ & $0 \%$ & 3 \\
\hline & T05 & $\begin{array}{l}\text { Suggest or Arrange } \\
\text { Social Support }{ }^{5}\end{array}$ & $13 \%$ & $73 \%$ & $15 \%$ & $0 \%$ & 2 \\
\hline & T08 & Antecedents & $8 \%$ & $75 \%$ & $17 \%$ & $0 \%$ & 1 \\
\hline \multirow[t]{8}{*}{$\begin{array}{l}50-74 \% \text { of } \\
\text { intended pathways }\end{array}$} & T06 & $\begin{array}{l}\text { Natural } \\
\text { Consequences }\end{array}$ & $10 \%$ & $51 \%$ & $39 \%$ & $0 \%$ & 1 \\
\hline & $\mathrm{T} 12$ & $\begin{array}{l}\text { Repetition and } \\
\text { Substitution }\end{array}$ & $8 \%$ & $60 \%$ & $33 \%$ & $0 \%$ & 0 \\
\hline & T13 & $\begin{array}{l}\text { Comparison of } \\
\text { Outcomes }^{5}\end{array}$ & $8 \%$ & $58 \%$ & $35 \%$ & $0 \%$ & 2 \\
\hline & T07 & $\begin{array}{l}\text { Shape Knowledge } \\
\text { of Behavior }\end{array}$ & $8 \%$ & $54 \%$ & $38 \%$ & $0 \%$ & 1 \\
\hline & T11 & $\begin{array}{l}\text { Associations to } \\
\text { Deter Unwanted } \\
\text { Behavior }\end{array}$ & $8 \%$ & $51 \%$ & $41 \%$ & $0 \%$ & 0 \\
\hline & T10 & $\begin{array}{l}\text { Associations to } \\
\text { Promote Wanted } \\
\text { Behavior }\end{array}$ & $8 \%$ & $50 \%$ & $42 \%$ & $0 \%$ & 0 \\
\hline & $\mathrm{T} 17$ & Mental Regulation & $4 \%$ & $63 \%$ & $33 \%$ & $0 \%$ & 2 \\
\hline & T09 & $\begin{array}{l}\text { Behavior } \\
\text { Observation }\end{array}$ & $1 \%$ & $63 \%$ & $32 \%$ & $4 \%$ & 1 \\
\hline \multirow[t]{2}{*}{$\begin{array}{l}25-49 \% \text { of } \\
\text { intended pathways }\end{array}$} & $\mathrm{T} 15$ & $\begin{array}{l}\text { Incentives and } \\
\text { Rewards }\end{array}$ & $8 \%$ & $35 \%$ & $56 \%$ & $1 \%$ & 0 \\
\hline & T19 & Self-Identity & $3 \%$ & $32 \%$ & $39 \%$ & $26 \%$ & 1 \\
\hline $\begin{array}{l}<25 \% \text { of intended } \\
\text { pathways }\end{array}$ & T18 & $\begin{array}{l}\text { Identity as Example } \\
\text { to Others }\end{array}$ & $6 \%$ & $7 \%$ & $87 \%$ & $0 \%$ & 0 \\
\hline
\end{tabular}




$\begin{array}{lllllll}\text { T16 } & \begin{array}{l}\text { Scheduled } \\ \text { Consequences }^{5}\end{array} & 1 \% & 1 \% & 1 \% & 98 \% & 0\end{array}$

${ }^{1}$ An intended pathway is one in which a model designates a maternal behavior as a target behavior by requiring or recommending that visitors promote it as a way to reduce a priority risk. ${ }^{2} \mathrm{~A}$ technique category is considered endorsed if the model either requires or recommends that the visitor use it in the context of an intended pathway. ${ }^{3}$ Number and name as in the Appendix. ${ }^{4}$ Model considered to designate the technique category as high-emphasis if it rated it a " 5 " for any of its intended pathways in Survey $3 .{ }^{5}$ Percentages do not total $100 \%$ due to rounding. 
Model-Specific Priority Risks, Target Behaviors, Intended Pathways and Stance on Technique Categories

Across Five Models

Mean Min - Max

Priority Risks, Target Behaviors and Intended Pathways

Number of Priority Risks

Number of Target Behaviors

Number of Intended Pathways

Stance on Technique Categories: Mean per Intended Pathway

Endorsed Technique Categories

Required Technique Categories

Recommended Technique Categories

Not Endorsed but Compatible Technique Categories

Incompatible Technique Categories

Stance on Technique Categories: Standard Deviation across Intended Pathways

Endorsed Technique Categories

Not Endorsed but Compatible Technique Categories

Incompatible Technique Categories

\begin{tabular}{ll}
\hline 9.2 & $7-10$ \\
\hline 11.2 & $5-14$ \\
\hline 31.6 & $16-41$
\end{tabular}

\begin{tabular}{ll}
13.8 & $1.5-20.0$ \\
\hline 3.2 & $0.0-8.9$ \\
\hline 10.6 & $1.5-20.0$ \\
\hline 8.0 & $1.4-20.5$ \\
\hline 1.2 & $1.0-2.0$ \\
\hline
\end{tabular}

\begin{tabular}{ll}
2.3 & $0.0-5.3$ \\
\hline 2.3 & $0.0-5.4$ \\
\hline 0.1 & $0.0-0.5$
\end{tabular}

Across Four Models ${ }^{1}$

Mean $^{2} \quad$ Min - Max

Within-Model Consistency in Endorsed Technique Categories across Intended Pathways

Pathways with Same Priority Risk but Different Target Behaviors

Same Endorsed Technique Categories

$30 \% \quad 0-71 \%$

Same high-emphasis Technique Categories

$32 \% \quad 0-50 \%$

Same Pattern of Emphasis for all Technique Categories ${ }^{3}$

$9 \%$

$0-25 \%$

Pathways with Same Target Behavior but Different Priority Risks

Same Endorsed Technique Categories

$31 \% \quad 0-75 \%$

Same high-emphasis Technique Categories

$62 \%$

$0-100 \%$

Same Pattern of Emphasis for all Technique Categories ${ }^{3}$

$50 \% \quad 0-100 \%$

${ }^{1}$ One model excluded because it had only one intended pathway meeting criteria for reporting emphasis on specific technique categories

${ }^{2}$ Average of each model's percent of intended pathways meeting indicator of consistency.

${ }^{3}$ Limited to technique categories endorsed across all intended pathways

\section{Appendix}




\section{Appendix. Technique Categories and Operational Definitions}

1. Assess Readiness for Change Gather information about the expectant woman's readiness to change the behavior.

2. Goals and Planning Assist the expectant woman to: set a behavior change goal; develop a plan to meet the goal using strategies to overcome barriers and increase facilitators; review her progress toward the goal; modify the goal or plan as needed.

3. Monitoring and Feedback Monitor the expectant woman's progress in changing the behavior; give feedback on that progress; establish ways for the expectant woman to self-monitor her progress.

4. Provide Social Support Directly provide the expectant woman encouragement, emotional support or practical help to perform the behavior.

5. Suggest or Arrange Social Support Suggest or assist the expectant woman to seek encouragement, emotional support or practical help to perform the behavior from a friend, relative, colleague, or group.

6. Natural Consequences Provide written, verbal or visual information about the behavior's health, emotional, social or environmental consequences; encourage her to assess her feelings after attempts to perform the behavior; raise her awareness of future regret about performing the unwanted behavior.

7. Shape Knowledge of Behavior Provide information or instruction to shape the expectant woman's knowledge of how to perform the behavior. This includes identification of behavioral 'triggers' and their perceived causes. 'Triggers' are thoughts or situations that lead to performance of the unwanted behavior.

8. Antecedents Change or support change of the expectant woman's physical or social surroundings to facilitate performing the behavior, create barriers to an unwanted behavior, or avoid cues to an unwanted behavior.

9. Behavior Observation Demonstrate the behavior; provide an observable example of the behavior; draw attention to others' performance of the behavior as a model.

10. Associations to Promote Wanted Behavior Identify, introduce, or alter social or environmental prompts or cues to promote the wanted behavior.

11. Associations to Deter Unwanted Behavior Identify, alter, or remove social or environmental prompts or cues to deter the unwanted behavior.

12. Repetition and Substitution Encourage the expectant woman to practice $p$ behavior or substitute it for an unwanted behavior.

13. Comparison of Outcomes Encourage the expectant woman to compare the pros and cons of changing the behavior, or to compare the outcomes of changing versus not changing the behavior. Includes encouraging the expectant woman's imagination or observation of either the consequences of the unwanted behavior or rewards for the wanted behavior.

14. Credible Source Present verbal or visual communication from a credible source in favor of or against the behavior.

15. Incentives and Rewards Provide or arrange for the expectant woman to receive a material incentive or reward (something of value) or a social incentive or reward (words of congratulation), or removal of an unpleasant consequence for making progress in performing the behavior. Includes encouraging the expectant woman to use selfincentives or self-rewards.

16. Scheduled Consequences Use a threat of future punishment or removal of a reward as a consequence of performance of an unwanted behavior; arrange for a negative consequence or punishment following performance of an unwanted behavior.

17. Mental Regulation Suggest strategies to minimize demands on the expectant woman's mental resources to make it easier for her to perform the behavior.

18. Identity as Example to Others Suggest to the expectant woman that performing the behavior might serve as an example to others.

19. Self-identity Assist the expectant woman to identify discrepancies between her behavior and her values or self-image; encourage her to self-identify as someone who used to perform the unwanted behavior; suggest her adopting a new perspective to change thoughts or emotions about the behavior.

20. Self-belief Promote the expectant woman's self-belief that she can successfully perform the behavior, for example by persuading her about her capabilities and encouraging her to mentally rehearse success, focus on past success or use positive self-talk.

21. Referral and Linkage Provide referral or information to link the expectant woman to a community resource to assist in performing the behavior; review progress in completing the referral; support connections in completing the referral or perform an interagency case review. 
22. Monitoring and Follow-up of Referral Review the expectant woman's experience accessing community resources to help her perform the behavior; assist in overcoming barriers to completing a referral.

23. Coordination with Other Services Ask about and act on the expectant woman's ideas on how to assist her in adhering to guidance from other providers regarding performing the behavior.

\section{Figures}

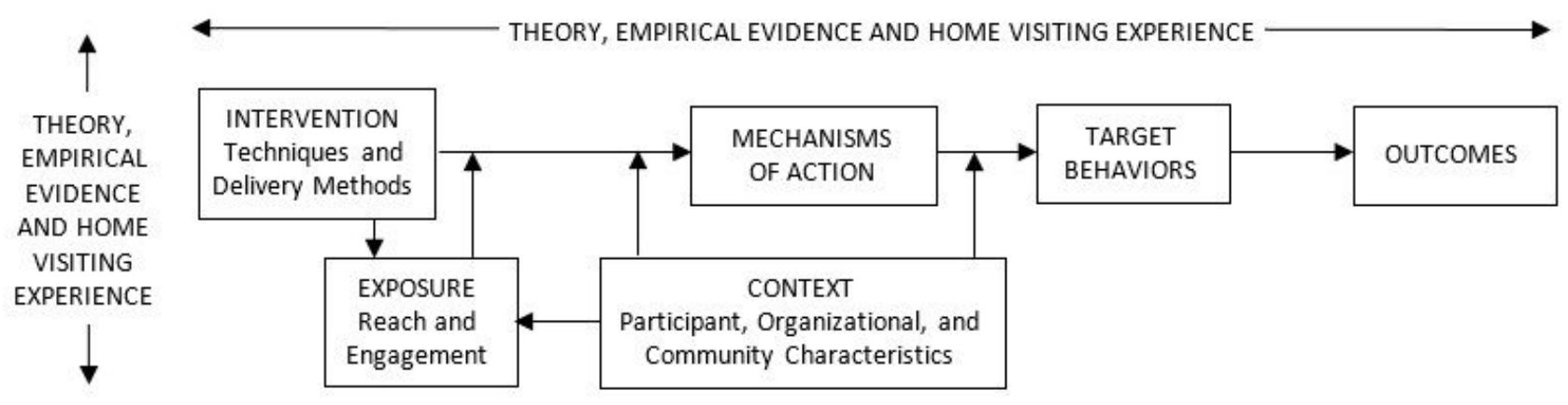

Figure 1

Home Visiting Precision Paradigm (adapted from the Human Behaviour Change Project19) The figure identifies key constructs and associations among them for designing and testing strategies to achieve precision home visiting as a way to achieve equity and, in so doing, broaden and strengthen impacts on outcomes efficiently. Specification of constructs and their associations is grounded in theory, empirical evidence and the experience of home visiting stakeholders. • Interventions within home visiting influence mechanisms of action such as knowledge, attitudes and skills. This, in turn, promotes target behaviors to achieve intended outcomes. Mechanisms of action and target behaviors are the mediators of intended outcomes. $\cdot$ The nature of the home visiting interventions influences success in reaching and engaging participants. This, in turn, moderates the influence of services on mechanisms of action. - Context moderates how well participants are reached and engaged, how well services influence mechanisms of action and how well this, in turn, promotes target behaviors. Context includes the attributes of participants providers and recipients - and of local implementing agencies and other organizations and the communities in which programs operate.

Survey 2

Which techniques should visitors use to promote specific behaviors to reduce specific risks?

\section{Survey 3}

How much emphasis should visitors give to using each technique?

\section{Survey 1}

Part 1. Which risks contributing to poor birth outcomes does the model aim to reduce?

Part 2. Which maternal behaviors does the model aim to promote to reduce these risks?

\section{Model Eligibility Criteria for Project}

- Evidence-based HV model

- Enrolls families prenatally

- Promoting good birth outcomes is a priority

\begin{tabular}{|c|c|c|}
\hline $\begin{array}{c}\text { INTERVENTION } \\
\text { Techniques to use to } \\
\text { promote target behaviors }\end{array}$ & $\begin{array}{c}\text { TARGET BEHAVIORS } \\
\text { to promote as a way to reduce priority } \\
\text { risks for poor birth outcomes }\end{array}$
\end{tabular}$\longrightarrow \begin{gathered}\text { OUTCOMES } \\
\text { Newborn gestational age } \\
\text { and birth weight }\end{gathered}$

Figure 2

Home Visiting Model Eligibility and Data Collection Mapped to the Home Visiting Precision Paradigm 


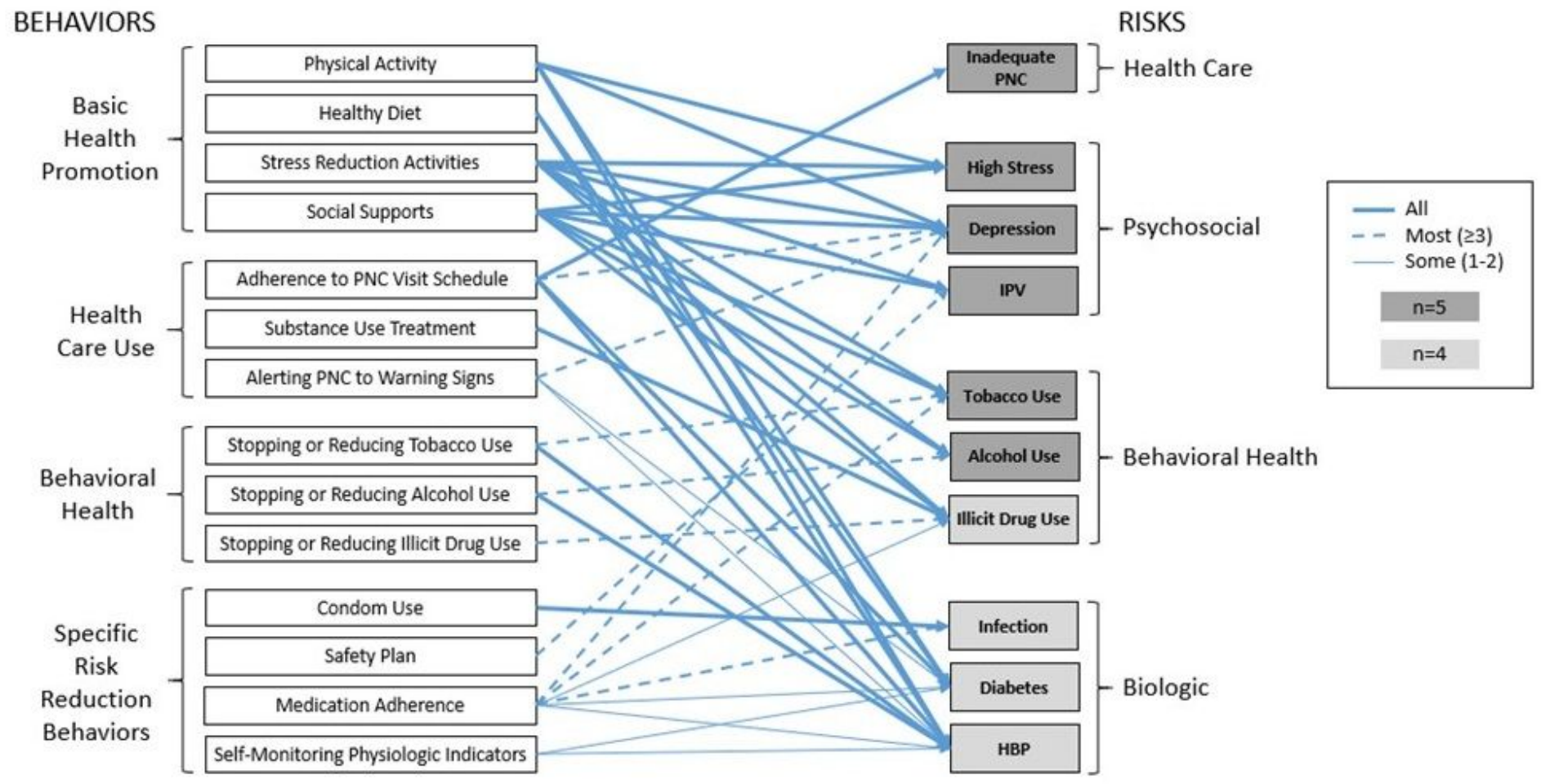

\section{Figure 3}

Models' Intended Pathways from Target Maternal Behaviors to Priority Risk

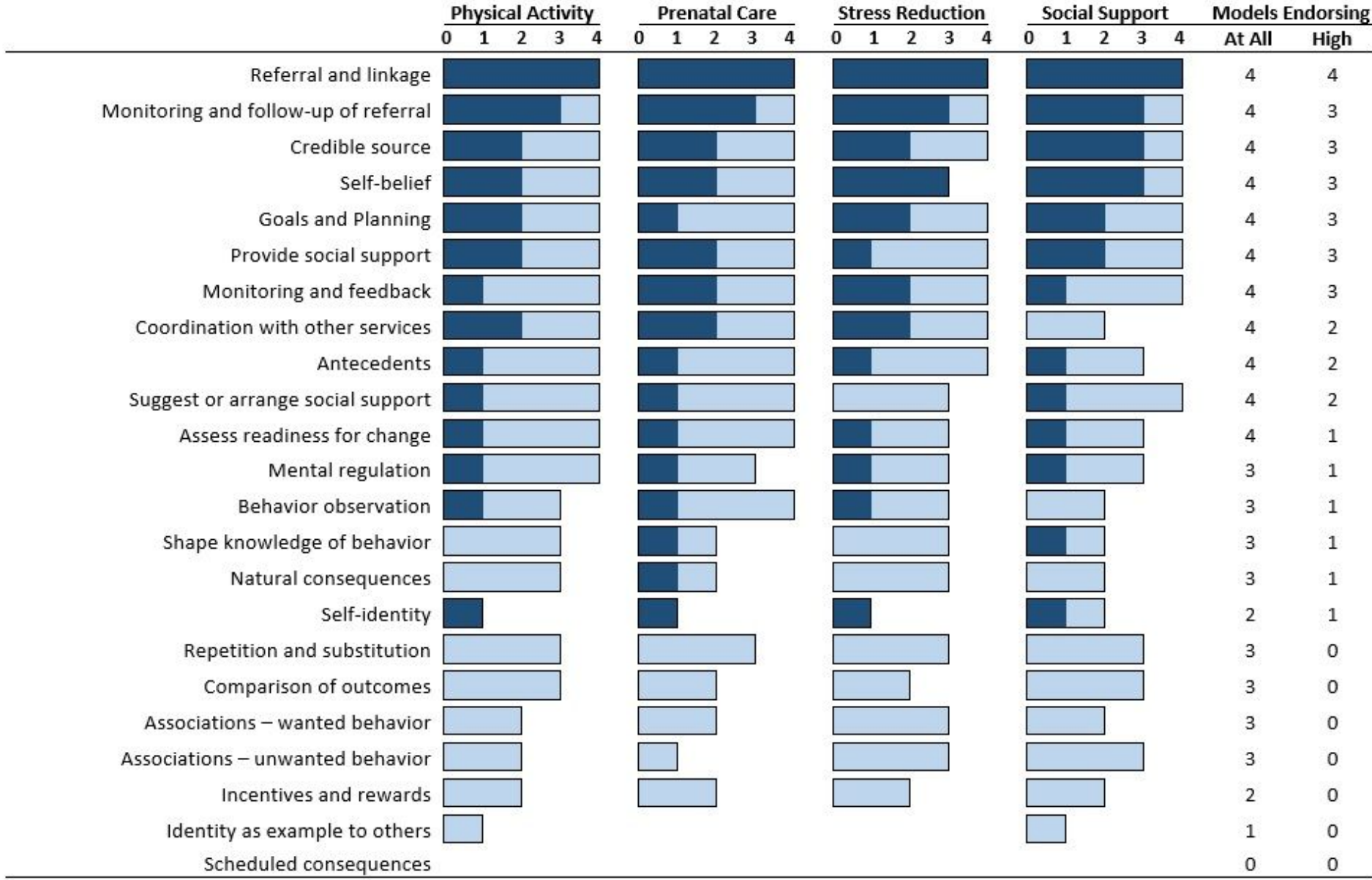


Figure 4

Models1 Endorsing and Emphasizing Technique Categories2 to Promote Four Target Behaviors to Reduce Maternal Depression. 1 Based on four models because one model did not endorse any technique categories for physical activity, stress reduction or social support, and did not consider prenatal care adherence as a target behavior to reduce risks of depression. 2 Dark shading = high emphasis of technique category; Light shading = low to moderate emphasis.

\section{Supplementary Files}

This is a list of supplementary files associated with this preprint. Click to download.

- STROBEchecklistv4combined.docx 